Mr Fry's bill is currently embroiled in debate in a House of Commons standing committee. The committee has so far amended the first six and three quarters of the bill's 38 clauses. At the current rate of amendment the committee will be sitting until August 1982.

Parliamentary procedure, however, will not allow Mr Fry's bill to last that long. It was introduced as a private member's bill and, as such, has to be passed into legislation this session if at all. If it fails to complete the course by late summer, it will have to go back to compete with other private members' bills in the ballot box for the next session.

The Halsbury Bill seems the more likely of the two to survive the parliamentary hurdles. It is also more likely to have the support of the scientific community because it does not advocate prior judgement of the value of scientific research with animals. Its amended form acknowledges and builds on the Protection of Animals Act 1911 but would repeal the Cruelty to Animals Act 1876. The 1911 Act prohibits general cruelty to animals, such as kicking, beating or over-working, and deals specifically with laboratory animals.

In re-drafting Lord Halsbury's Bill, the House of Lords select committee has also produced a report summarising the evidence it has taken and the need for new legislation. The report, which was made available to Nature last week, butit is not yet publicly available, says that new legislation is needed because of the great increase in the number of animals used in laboratories over the past century and the greater variety of procedures, not in practice in 1876 , to which they may be subject.

Lord Halsbury's Bill follows the 1876 Act in requiring all experimenters with animals to obtain a licence from the Home Office. However, it differs in demanding greater specification by those applying for a licence of the number and type of animals to be used and the procedures to be done on them. Applicants for licences would also be required to state the degree of pain or suffering likely to be experienced by the animal and the measures that would be taken for relieving it.

Lord Halsbury's Bill also incorporates the 'pain' and 'anaesthesia' conditions. These are that an animal that appears to be suffering severely under any procedure must be given immediate relief or be humanely killed, and that animals undergoing procedures which may be expected to cause severe pain or suffering must be properly anaesthetised before the procedure starts, be relieved of any pain afterwards or killed humanely. If this is not feasible it should be humanely killed. The 'pain' and 'anaesthesia' conditions are not written into the 1876 Act, though they have been effectively enforced by the Home Office cruelty to animals inspectorate.

Other points of difference between the 1876 Act and the Halsbury bill concern
- the nature of the sponsors. Both require applicants for licences to have two sponsors; the 1876 Act says that one must be a professor of biology, the other a president of a learned biological society; the Halsbury Bill says that the two sponsors must be chosen from a panel nominated by the Secretary of State.

- the term of licences. The Act allows licences to run indefinitely, the Halsbury Bill for only five years.

- the constitution of an advisory committee. The 1876 Act does not provide for an advisory committee on laboratory animals, although one has been in operation since 1906. The Halsbury Bill would incorporate the advisory committee in the legislation and would give it greater powers than at present. For example, the committee would be required to monitor the extent to which animals are used in painful or stressful procedures, review the possibility of alternatives, and inform the Secretary of State on public opinion. It would also have to consider ethical matters.

- the function of a code of practice. One does exist, although it is not written into the 1876 Act. The Halsbury Bill would incorporate it, increase its status to the equivalent of othe highway code in Britain. Although infringement of the code would not constitute an offence in itself, it could be used as evidence against someone suspected of malpractice.

- batch testing of sera and vaccines. This is not included under the 1876 Act but would be under the Halsbury Bill. Under this provision, the number of procedures notified to the Home Office and the number of licences would increase considerably. Although the idea behind the Halsbury Bill is to include procedures not covered at present, most survey, field, and school work would be exempt. For example, simple injecting of animals or ringing birds would not be included.

- species of animals covered. The 1876 Act covers all vertebrates; the Halsbury Bill would extend protection to chordates and embryos or larvae capable of independent existence.

The Halsbury Bill is also broader in scope than the existing legislation. But it does not specify detail, preferring to leave that to the secretary of state. For example, he would be able to extend the bill to include other species if he chose. He would also appoint the advisory committee.

The amended Halsbury Bill will go to a committee of the whole House of Lords on 20 June. Once it has been through the report stage, it can be presented to the Commons but it is unlikely that the Commons will consider it before next session. It could then be thrown back at the Lords. Although some believe that new legislation could be passed this year, others believe that the government is likely to stick to its plan of seeing the European Convention first.

Judy Redfearn
$\mathrm{X}$-rays

\section{Selling a new source}

THE European Science Foundation -normally a quiet body conducting its catalytic business behind the closed doors of committee rooms - is supporting a proposal that Europe should spend $£ 55$ million on a new, $5 \mathrm{GeV}$ super-bright European Synchroton Radiation Source (ESRS). Last week at Daresbury, UK, it tried to convince the British synchrotron users that it was right. The result was cautious approval.

Britons are probably the hardest to convince of the case. Their own dedicated source, the SRS, will start producing data at Daresbury later this year, and it will be well ahead of other European sources (see figure). Moreover their purse-holder, the Science Research Council, is committed to other large accelerator projects (the Nuclear Structure Facility at Daresbury and the Spallation Neutron Source at the Rutherford Laboratory) up to 1984. And the cash available to run the SRS will only be enough to operate half its beam ports.

The challenge, though, comes from the US. The $£ 12$ million National Synchrotron Light Source - a two-stage source under construction at Brookhaven Laboratory, Long Island - will come on line in July $1981(0.7 \mathrm{GeV})$ and October 1981 (2.5 $\mathrm{GeV})$. The second stage should exceed the brilliance of the $2 \mathrm{GeV}, £ 5$ millions SRS by a factor of ten - giving the SRS just a year as world leader.

So Yves Farge, chairman of the ESF ad hoc committee on synchrotron radiation and director of the DCI synchrotron radiation laboratory at Orsay, France, argued last week that Europe will need a more advanced source if it is not to be in the second league. Pressure is also high from countries without access to a national synchrotron source - particularly the Scandinavians, Belgium and The Netherlands - for a European facility to be built.

According to Farge, the Scandinavians - will make the construction of the ESRF a condition of their acceptance of LEP, the next high energy physics accelerator contemplated by the European centre for nuclear research (CERN). The Scandinavian view, says Farge, is that the ESRF should be constructed in the tunnel vacated when the CERN intersecting storage rings (ISR) are shut down as a preliminary to LEP.

Farge is unhappy about that approach, however. There are no biologists at CERN, and one of the attractions of synchrotron radiation is that it is a general tool of structural analysis useful to most disciplines. Biologists, however, would feel isolated at CERN. It would be better, he 
feels, to choose a different site and set up a private association to which national research councils could contribute, avoiding the need for complex international agreements. (There is a similar foundation at the Institut Laue

There is also a rapidly increasing interest in synchrotron radiation in industry, Farge believes. DCI at Orsay profited from industrial participation by $£ 5,000$ in 1979 , and the figure will be $£ 20,000$ this year. Oil companies appear to be interested in the routine use of the light to seek out significant trace elements in core samples for oil prospecting; the X-ray intensity available could give them a factor of 1,000 in speed.

However the ESRF itself is a long way from a final design. A sub-group of Farge's committee, headed by Dr D J Thompson of Daresbury, has prepared a preliminary study which defines a $5 \mathrm{GeV}, 0.5 \mathrm{Amp}, 604$ $\mathrm{m}$ circumference ring with the brilliance function shown in the figure. Drs B Buras and G V Marr have also defined a shopping list of instrumentation. The machine and building plus half the instruments would cost $£ 55$ million at present prices, and could be constructed within 3 to 6 years.

But a new idea has occurred to the committee: that it be an "all-wiggler" machine, a design in which the experimental radiation is taken not from the main bending magnets of the ring, but Langevin at Grenoble.)

from multipole, high field magnets which introduce local high curvature wiggles in the beam path. This would enable the machine to use lower energy and beam current for the same radiation intensity. And the overall radius, as it happens, would be "just right" for the CERN ISR tunnel.

The uses of the ESRF radiation would stretch from molecular biology to nuclear physics, the meeting was told. Using 'undulators' - wigglers with $50-100$ poles that produce coherent radiation - spectral brilliances up to seven orders of magnitude greater than those obtainable at DCI are conceivable. Such increases are very rare in science, said Farge, and the consequences are unpredictable.

However Daresbury's Dr Mike Hart, who took the role of the ESRF's chief bubble-burster, claimed one thing is predictable: that such an intensity of radiation from the undulator would destroy most samples. Quick calculations by Farge and Thompson led to estimates of 33-300 Watts onto the sample. "You'll have cooling problems,"' says Hart.

Probably the most exciting application of the high intensity, coherent light from an undulator would be to illuminate a zone plate X-ray microscope - one that depends on diffraction effects to produce focusing and de-focusing equivalent to the lenses of an ordinary light microscope. This application is limited by the fineness

\section{WAVELENGTH $(\AA)$}

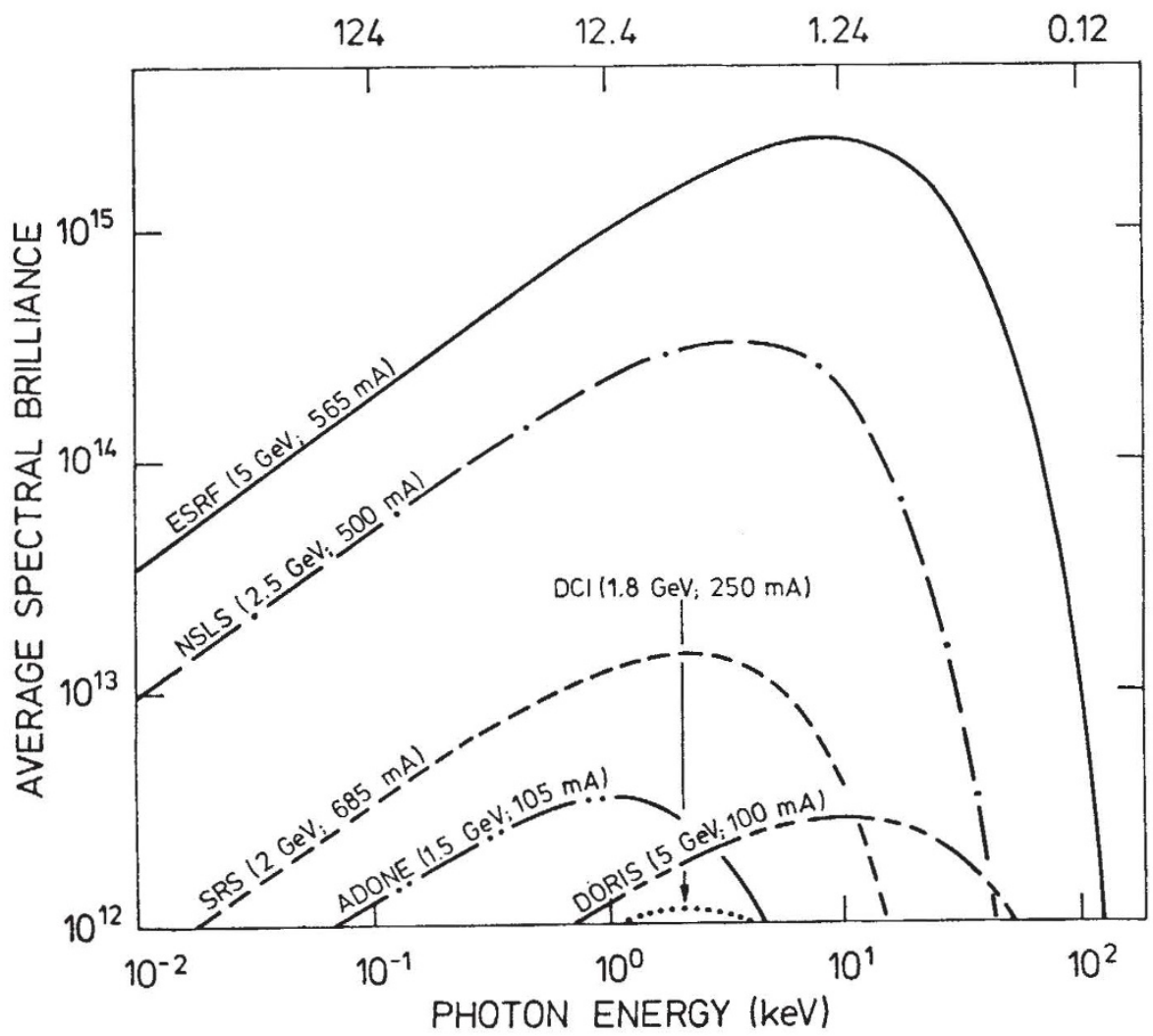

Spectral brilliance (in photons $s^{-1} \mathrm{~mm}^{-2} \mathrm{mrad}$ in $0.1 \%$ bandwidth) is compared for the proposed ESRF, the Brookhaven NSLS (ready

October 1981), the Daresbury SRS (October 1980), and the Frascati ADONE, the Hamburg DORIS and the Orsay DCI (in operation). with which zone plates can be drawn, but object resolutions of 100 Angstroms are foreseeable; and with a wavelength of $25 \mathrm{~A}$, tuned to detect carbon but not oxygen, the prospect opens of following ultrastructural movements in live cells.

Nevertheless the ESF has not argued the case sufficiently for the ESRF as against existing synchrotron light sources, says Hart; $70 \%$ of the arguments used in the ESF document "the scientific case" for the ESRF apply to synchrotron radiation in general, and not to the ESRF in particular. The document will have to be rewritten in two years' time, Farge admits.

Robert Walgate

Four documents on the ESRF are available from the European Science Foundation, 1 quai Lezay-Marnesia, F-67000 Strasbourg, France: 'The Feasibility Study', 'The Scientific Case', 'The Machine', and 'Instrumentation'.

\section{Training}

\section{Thoughts from the think tank}

THE British government's own think tank, known as the Central Policy Review Staff (CPRS), published last week a mildly subversive prescription for making the products of the British educational system more suited to what is called "the world of work". The CPRS report ("Education, Training and Industrial Performance", HMSO, £4.25) gives no explanation of how it came to be published or even written.

Among the points at which the recommendations of the report may seem at odds with current government policy, the following are conspicuous:

- There should be formal standards and qualifications for skills acquired by means of vocational training.

- The government should continue to provide vocational training for young unskilled workers.

- More attention should be paid, especially in the age range $16-18$, to the acquisition of practical skills, preferably in colleges of further education, not schools.

The CPRS does however accord with current government policy in its advocacy of a core curriculum (consisting of English, mathematics, science, a practical subject and "possibly" a foreign language) in the age range 11-16. The report also asks that the financing of further education by public loans should be reconsidered.

The CPRS is suitably modest in its acknowledgement of how little is known of the relationship between education training of any kind and the eventual benefits to employers and the national economy. There is no single issue on which a government initiative would, in the CPRS's judgment, make training radically more effective - and, even if there were, implementation would be hampered by the 